\title{
ENTRE O PASSADO E O PRESENTE: CORPOS QUE DIVERGEM ${ }^{1}$
}

\author{
${ }^{2}$ Katiuscia Angélica Micaela de Oliveira - UNESC \\ ${ }^{3}$ Marcos Paulo da Silva Costa- UNESC
}

\section{INTRODUÇÃO}

$\mathrm{Na}$ busca de relações e deslizamentos da imagem na arte, a pesquisa em questão confrontou relações entre a arte clássica e a contemporânea, com ênfase na pintura de Hieronymus Bosch, obra Tríptico do Jardim das Delícias e no videoclipe Trópico de Lana Del Rey. Na perspectiva de gerar interpretações semelhantes e diferentes em relação a metáforas da criação do mundo (o jardim do Éden), fazendo comparação com o presente, apresentando o que seria a atual humanidade e a fragmentação de um possível futuro da mesma humanidade. Tanto a pintura quanto o videoclipe carregam suas especificidades de elementos humanos, espécies botânicas e cenários exóticos, animais imagéticos, que se correlacionam no contexto geral da falácia da criação do mundo. Fazer relação com ambas as obras, faz objetivar o interesse das relações dos movimentos da arte e das suas linguagens, criando novas perspectivas sobre a estética da arte.

Entre o passado e o presente: corpos que divergem é o ponto de partida para a pesquisa, tendo como a obra de Bosch na Idade Média representando os corpos de Adão e Eva, como sendo as primeiras criações, fazendo relação com o videoclipe de Del Rey, ambos apresentando esses corpos e mantendo uma ordem histórica, diferenciando apenas no último fragmento do vídeo.

\section{FUNDAMENTAÇÃO TEÓRICA}

HIERONYMUS BOSCH - OBRA TRÍPTICO DO JARDIM DAS DELÍCIAS

\footnotetext{
${ }^{1}$ Texto foi apresentado:

IV SELEP-Seminário de Leitura e Produção Textual. Língua, linguagem e arte, 2015 Unesc. II Congresso Ibero-Americano de Humanidades, Ciências e Educação: Políticas de formação nos Países lbero- Americanos, 2016 Unesc.

${ }^{2}$ Katiuscia Angélica Micaela de OLIVEIRA- Docente- UNESC Criciúma

${ }^{3}$ Marcos Paulo da Silva COSTA- Discente -UNESC Criciúma
} 
Jeroen van Aeken, cujo pseudônimo é Hieronymus Bosch, ('sHertogenbosch, c. $1450 / 9$ de agosto de1516), foi um pintor e gravador Holandês dos séculos XV e XVI. A época em que Bosch viveu foi durante a Baixa Idade Média, tendo em vigor o poder e a autoridade da Igreja, alguns pesquisadores e teóricos se contradizem a respeito de sua relação com ela. Na pesquisa as obras e bibliografias de Bosch encontram-se controversas em questões referentes aos ícones das suas obras,

Bosch era um moralista que desprezava as classes inferiores e não tinha simpatia alguma pelos pobres; e que fizera uma sátira mordaz e amarga em suas representações de mendigos, monges e freiras, soldados e camponeses, prostitutas, peregrinos e andarilhos (COPPLESTONE, 1997 p. 6).

O artista Bosch filho da Idade Média difere-se dos exemplos da arte desta época, sendo muito moderno para seu tempo, dividindo seu trabalho em duas vertentes distintas: realista e fantástica. Nota-se a crueldade e o modelo de dor das figuras humanas de total realismo que vão além da cultura da época e as figuras híbridas e místicas que atormentam o observador, pela criatividade e vivacidade das imagens, que trazem um realismo crítico.

Na obra Tríptico do Jardim das Delicias, sua parte exterior ao ser fechada cita o terceiro dia da criação do mundo, em seguida o painel divide-se em três parte internas, sendo: painel esquerdo $O$ Jardim do Éden, painel central $O$ Jardim das Delícias Terrenas e painel direito O inferno.

\section{PAINEL ESQUERDO: O JARDIM DO ÉDEN}

A cena (COPPLEATONE, 1997) ilustra a Terra repleta de animais, reais e simbólicos como o unicórnio, símbolo fálico. Plantas de estrutura exótica, ao centro, a Fonte da Vida, mais abaixo surge a figura de Deus, sendo representada com características de Jesus Cristo vestindo uma túnica. Eva e Adão se encontram nus, estando ele sentado e ela encontra-se ajoelhada, segurando a mão de Deus. Ao lado 'Árvore do bem e do mal' (uma palmeira) tendo ao redor dela, a serpente tentadora.

\section{PAINEL CENTRAL: O JARDIM DAS DELÍCIAS TERRENAS}


Em uma paisagem com organização semelhante ao Jardim do Éden, plantas e animais exóticos se misturam com um emaranhado de figuras femininas e masculinas nuas. Segundo (COPPLEATONE, 1997 p. 56) "formas humanas que se entregam à alegre batalha entre os sexos, em contemplação onírica do amor, gestos ou posturas sexualmente incitantes, e em abraços explicitamente sexuais". Ao centro da obra um lago, também apontado como a fonte da juventude, onde mulheres se banham, e ao redor homens cavalgam. Em adição (COLEÇÃO, 1997 p.46) "A referência à luxúria e a outros pecados é dada pelos animais que participam do passeio a cavalo".

Acrescenta (COPPLEATONE, 1997 p. 56) acontece um "curioso efeito geral de orgia pastoral é de pacífica inocência e de uma delícia verdadeira". Mostram-se todos os tipos de relações sexuais e cenas eróticas, heterossexuais e homossexuais. Aparecem também relações eróticas ou sexuais entre animais, e mesmo entre plantas.

Os teóricos divergem, mas todos acentuam as simbologias de cada animal e planta da tela. Os detalhes da pintura oferecem especulações intrigantes, mas que abordam um pensamento principal que é a luxúria da humanidade, corpos que se entrelaçam sucumbentes pelo pecado. O pecado que foi promovido pela figura feminina. Segundo Bosing (1973 pg.56) "[...] era sempre a mulher que seduzia o homem para o pecado e para concupiscência, seguindo 0 exemplo de Eva."

\section{PAINEL DIREITO: O INFERNO}

O inferno é fortemente representado por corpos em deformações, em atos de erotismo, em defecação e corpos desmembrados. Figuras demoníacas e figuras humanas representam alguns pecados, como a gula e o orgulho.

A obra também é conhecida como "O inferno musical", pelas múltiplas representações musicais que aparecem associadas às figuras humanas. Inumeráveis tormentos associados a uma imensa máquina de tortura, aludindo uma humanidade pecaminosa que está condenada a minuciosos castigos no inferno real.

\section{LANA DEL REY-VÍDEO CLIP TRÓPICO}


Elizabeth Woolridge Grant nasceu em Nova lorque, 21 de junho de 1985 e ficou mundialmente conhecida pelo pseudônimo artístico Lana Del Rey. Cantora, compositora, modelo fotográfica, atriz e roteirista, é conhecida por seu estilo retrógrado das décadas de 1950 e 1960, sendo uma referência hipster, indie e vintage. Del Rey começou a compor com 18 anos e começou a se apresentar em bares de Nova lorque aos 21 anos.

O videoclipe curta metragem Tropico foi estreado no Cinerama Dome, em Hollywood, Califórnia, em 04 de dezembro de 2013, sendo em três partes representadas respectivamente pelas músicas Body Eletric, Gods and Monsters e Bel-Air. O filme transita entre a pureza original do Jardim do Éden, a vida pecaminosa do presente atual e a redenção divina.

\section{PRIMEIRO FRAGMENTO DO VIDEOCLIPE: BODY ELECTRIC}

O filme inicia com os personagens de Adão (Shaun Ross) e Eva (Lana Del Rey), no Jardim do Éden também chamado de Jardim do Paraíso. Deus é representado por um personagem fílmico John Wayne, e também entram em cena Jesus, Marilyn Monroe (personagem fílmico) e Elvis Presley (personagem fílmico), todos presentes com Adão e Eva - então Body Electric começa a tocar.

O filme todo é exibido com cenas de Del Rey intercalando em duas personagens, ora entra em cena como Maria, a mãe de Jesus trajando roupas azuis e véu, ora como Eva vestida com tapa sexo de flores.

O cenário deste momento do videoclipe apresenta películas saturadas, como uma névoa passando pela cena. Flashes de luz perpassam os personagens deixando uma aura que alude a corpos sagrados. Os personagens se misturam entre figuras humanas fílmicas, figuras humanas históricas religiosas e animais imagéticos, exemplos: unicórnio branco, animais reais, como coelhos e ovelhas brancas. A vegetação suscita pinturas impressionistas, com acúmulo de cor confundindo as formas, plumas no ar auxiliam na ficção. Cada integrante da cena comunica-se como em um monólogo antes do início da canção. Eva inicia a canção que fala: 
Elvis é meu pai, Marilyn minha mãe. Jesus é meu melhor amigo

Nós não precisamos de ninguém, porque nós temos um ao outro Ou pelo menos é o que eu acho. Nós relaxamos toda sexta à noite Dançando e rebolando sob a luz do luar (vagalume/lanadelrey)

Eva no embalo da canção dança e canta, seu corpo convida Adão a seguir seu ritmo. Os corpos se entrelaçam como num ritual de sedução, onde a figura feminina incita a performance/dança e a figura masculina rende-se a sedução. Os personagens já citados e Maria aparecem e reaparecem intercalando a cena com Adão e Eva. Assim desenvolvem a cena até o aparecimento da serpente na Árvore do Conhecimento do Bem e do Mal, que Eva a toca com intimidade. Uma peculiaridade é que a serpente é albina e o personagem Adão também, usando a cor branca como símbolo de pureza.

A serpente desaparece de cena e surge a maçã de um vermelho resplandecente que Eva segura de forma novamente sedutora mordendo-a. Adão morde a maçã em seguida. Eva e Adão desfalecem no chão e flashes de luzes com relâmpagos anunciam uma mudança de tempo. Imagens desta cena e da cena seguinte aparecem e desaparecem anunciando um fim e um novo começo. Teriam abandonado a pureza e herdado o pecado, expulsos do jardim e agora mortais, vivem no presente tempo moderno.

\section{SEGUNDO FRAGMENTO DO VIDEOCLIPE: GODS \& MONSTERS}

Eva aparece deitada no chão vestida com roupas íntimas vermelhas e sensuais com notas de dinheiro, uma dançarina stripper. A cena tem início em uma casa noturna, portanto o lugar agora não é mais sagrado nem divino, mas sim um lugar de luxúria e materialidade, onde mulheres dançam e homens oferecem dinheiro por seus corpos. Lana Del Rey está entre as dançarinas.

A imagem da Virgem Maria aparece e desaparece várias vezes em toda cena. Neste novo tempo moderno, o antigo casal sagrado dá lugar a um casal mundano e profanado. Adão e Eva vivem em Los Angeles, que é conhecida como a cidade do pecado, estando ele sujeito a um trabalho maçante, 
como resultado de sua expulsão. Eva aparece no mercado e inicia um jogo de sedução com Adão e a música sendo cantada:

Em uma terra de deuses e monstros Eu era um anjo. Vivendo no jardim do mal

Estragada, amedrontada Fazendo tudo o que eu precisava Brilhando como um farol de fogo Você tem esse remédio que eu preciso Fama, licor, amor. Dê-me isto devagar (vagalume/lanadelrey)

As cenas se alteram e repetem de forma rápida, onde os cenários são a boate, o mercado, paisagens urbanas sendo vistas do alto de colinas, ambas aparecem mulheres e homens com seus corpos profanos, semi-nus, erotizantes, usando drogas, álcool, cigarros, com armas incitando a violência. Seus rostos expressam uma satisfação com o uso das drogas, mas também uma tristeza, de forma pictórica que são pessoas monstros, cadáveres vivos. A maçã da primeira parte do videoclipe reaparece sendo novamente mordida.

Termina a música e Eva (Del Rey) recita o poema "Howl" de Allen Ginsberg, na cena aparece um grupo de homens ricos de meia idade comstrippers em um apartamento, corpos femininos em performance de sedução e orgias.

Novamente aparecem os flashes de luz e raios identificando o final, remetendo ao novo tempo.

\section{TERCEIRO FRAGMENTO DO VIDEOCLIPE: BEL AIR}

Deus, personagem fílmico John Wayne, aparece narrando o poema de John Mitchum "Porque eu amo a América?" (Deus profere: "Você me pergunta por que eu a amo? Bem, dei-me um tempo. Vou explicar. Você já viu um pôr do sol em Kansas, ou uma chuvarada em Arizona?"). Novo cenário, um campo com pastagens de um dia ensolarado, a imagem traz um brilho extravagante que perpassa as plantas e árvores. O casal aparece usando roupas pretas em um carro antigo. Iniciam uma troca de roupas para novas peças brancas, se desfazem das jóias e acessórios. Seus corpos aparecem submersos em água como no ritual de um batismo, induzindo a uma purificação. Não é possível identificar de onde vem à água, o elemento apenas se faz presente. 
Plumas aparecem em todo cenário e o casal inicia uma dança, mas desta vez os movimentos carregam uma pureza e ingenuidade. Os corpos agora com representação sagrada se entrelaçam como em uma comunhão e levitam aos céus como se estivessem purificados. A cena acontece ao som da música "Bel-Air".

Gárgulas em frente ao seu portão Tentando me dizer para esperar. Mas eu mal posso esperar para ver você. Então corro como se estivesse louca Até as portas do paraíso. Não quero ser má (vagalume/lanadelrey)

\section{METODOLOGIA}

Determinação do "estado da arte" e revisão empírica. O foco principal de observação são os corpos humanos 'Adão' e 'Eva', elementos figurativos emblemáticos do sexo feminino e masculino e suas relações, gerando discussões sem pretensão de censurar ou subjugar, e sim com a proposta de confrontar e construir novos conceitos. A tese da pesquisa tem como foco os corpos que divergem tanto na representação de Bosch em sua obra, quanto no videoclipe de Del Rey. A organização de pesquisa parte da observação, análise, relato, hipóteses e referencial teórico.

\section{ANÁLISE DE DADOS}

A obra de Bosch Jardim das Deliícias é um emaranhado de informações visuais que propõe diversas interpretações, análises e hipóteses, sendo que esta apreciação é de forma inicial e pequena, pois é apenas o início da pesquisa.

No videoclipe Trópico as letras das três músicas colaboram para a composição visual, produzindo uma obra diferente de clipes de divulgação de uma banda, pois a imagem do trópico é inerente e fundamental na apreciação. A performance corporal, o cenário, a música o enredo fílmico e demais elementos visuais compõem a produção.

As obras direcionam à questões que intimaram, mas que não demos conta de responder. Seguem algumas: Como esses corpos se movimentam na 
anacronia do tempo? A imagem dos corpos femininos é subjugada pelos corpos masculinos? Como podemos identificar a representação dos corpos enquanto profano e sagrado? Qual a narrativa destes corpos nas obras em questão?

\section{CONCLUSÃO}

Os deslizamentos entre a arte clássica e a contemporânea são de grande valia na pesquisa da arte. Buscar elementos da arte no passado e fazer ligações com o presente, na arte contemporânea, proporciona um amadurecimento e potencializa novos conceitos na estética da arte. A pesquisa na obra de Hieronymus Bosch, o Tríptico do Jardim das Delícias, possibilitou a percepção de uma riqueza simbólica contida em tão pequeno espaço físico, e o quanto estes elementos visuais se aproximam dos elementos usados no videoclipe Trópico de Lana Del Rey, mostrando figuras exóticas e fantásticas, criando uma das tantas ligações com a obra de Bosch. Por mais que os artistas contemporâneos neguem a inspiração artística no passado, as lembranças contidas no inconsciente da imaginação coletiva estão presentes em suas obras.

Relacionar os movimentos da arte e das suas linguagens, a pintura, a dança, performance, teatro, música, cinema, proporcionou perceber especificidades que partilham do mesmo objeto de estudo, gerando um olhar diferenciado para a estética da arte. Os corpos inseridos na pintura de Bosch e no vídeo clip de Del Rey promovem uma reflexão e conscientização do processo de criação de cada artista. As duas linguagens da arte conseguiram apresentar esses corpos em situação de performance referenciando o profano e o sagrado, mesmo esses estando em contextos históricos e tempos diferentes. A pesquisa apenas iniciase, pois, os corpos que divergem em nossa contemporaneidade são objetos de estudo que demandam tempo e novos olhares sobre este tema que tanto instiga e perturba seus admiradores.

\section{REFERÊNCIAS:}

BOSCH: Vol. 19 - Coleção Grandes Mestres ABRIL .1ª ED. Abril 1977.

BOSING, Walter. Hieronymus Bosch. Benedikt Taschrn, 1991.

COLEÇÃO de arte : Bosch. São Paulo: Editora Globo, 1997. 41 p. 
COPPLESTONE, Trewin. Vida e obra de $\mathrm{H}$ ieronymus Bosch/ Trewin Coplestone; Tradução de Bazán Tecnologia e Linguística, Liza Melle.-Rio de Janeiro: Ediouro, 1997.

VEVO. Short Film. Disponível em: <www.vevo.com/watch/lana-del-rey/tropico(short-film)-(explicit)/GBUV71301124> Acesso em: 07 nov. 2016. 